\title{
TROPICAL CIRCULATIONS AND THE ASSOCIATED RAINFALL ANOMALIES DURING TWO CONTRASTING YEARS
}

\author{
MARY TOSHIE KAYANO, VADLAMUDI BRAHMANANDA RAO AND ANTONIO DIVINO MOURA \\ Instituto de Pesquisas Espaciais -INPE, Ministério de Ciência e Tecnologia-MCT, C.P. 515-1220l-São José dos Campos. SP, Brasil
}

Received 22 October 1987

Revised 25 February 1988

\begin{abstract}
The severe drought conditions observed during 1983 over a large extent of tropical lands were associated with the 1982-1983 El Niño event. In contrast, above normal rainfall was observed over these areas during 1984. The tropical circulations have been examined for these two contrasting years. The intensity and location of the rising and sinking motions were consistent with the rainfall anomalies and also with the outgoing longwave radiation anomalies. It was found that the north-south migration of the tropical trough played an important role in modulating the tropical rainfall during these two years. In the context of the currently acceptable theoretical notions of the tropical circulation, some of the observed characteristics could be explained in terms of an atmospheric response to tropical heat sources. The results suggest that seasonal changes were involved in the 1982-1983 El Niño collapse.
\end{abstract}

KEY wORDS Precipitation. Interannual variation. Tropical circulations

\section{INTRODUCTION}

The El Niño/Southern Oscillation (ENSO) event of 1982--1983 has been the most pronounced and by far the best documented event of this century (Rasmusson and Wallace, 1983). It led to massive dislocations of the rainfall regimes of the tropics, bringing drought to some areas and torrential rains to otherwise arid regions. News media and several recent articles (Chen, 1983; Krueger, 1983; Quiroz, 1983; Rasmusson and Wallace, 1983; Kousky et al., 1984) have described the development phase of this event. The purpose of this paper is to study the tropical circulations for the two contrasting years, 1983 and 1984. In terms of the Southern Oscillation (SO), 1983 registered a strong negative index, and in 1984 the SO index returned to normal values. Even in terms of the precipitation anomalies, the patterns approximately reversed between 1983 and 1984 . In this paper the rainfall characteristics in the tropics are examined with special emphasis on the South American region.

\section{DATA AND METHODOLOGY}

The equatorial circulations in the vertical zonal plane for selected seasons of 1983 and 1984 are calculated using the National Meteorological Center (NMC) tropical grid point wind data, which were available as monthly means. These data were given at $5^{\circ}$ grid intervals in longitude and variable intervals from $5^{\circ}$ to $3.5^{\circ}$ in latitude at the $1000,850,700,500,300$ and $200 \mathrm{mb}$ levels. The monthly rainfall data analysed here are for the tropical areas between $10^{\circ} \mathrm{N}$ and $10^{\circ} \mathrm{S}$ of South America, Africa and the Indonesian region (Figure 1). Data for north-east Brazil were obtained from Superintendência do Desenvolvimento do Nordeste (SUDENE) of Brazil; data for Peru and Ecuador were acquired through personal contacts; other series were extracted from the Monthly Climatic Data for the World and also from the data bank of the Departmento Nacional de Águas e Energia Elétrica (DNAEE) of Brazil. The precipitation data were supplemented or checked using the information found in the Boletim Agroclimatológico of the Instituto Nacional de Meteorologia of Brazil.

0196-1748/88/050477-12\$06.00

(C) 1988 by the Royal Meteorological Society 

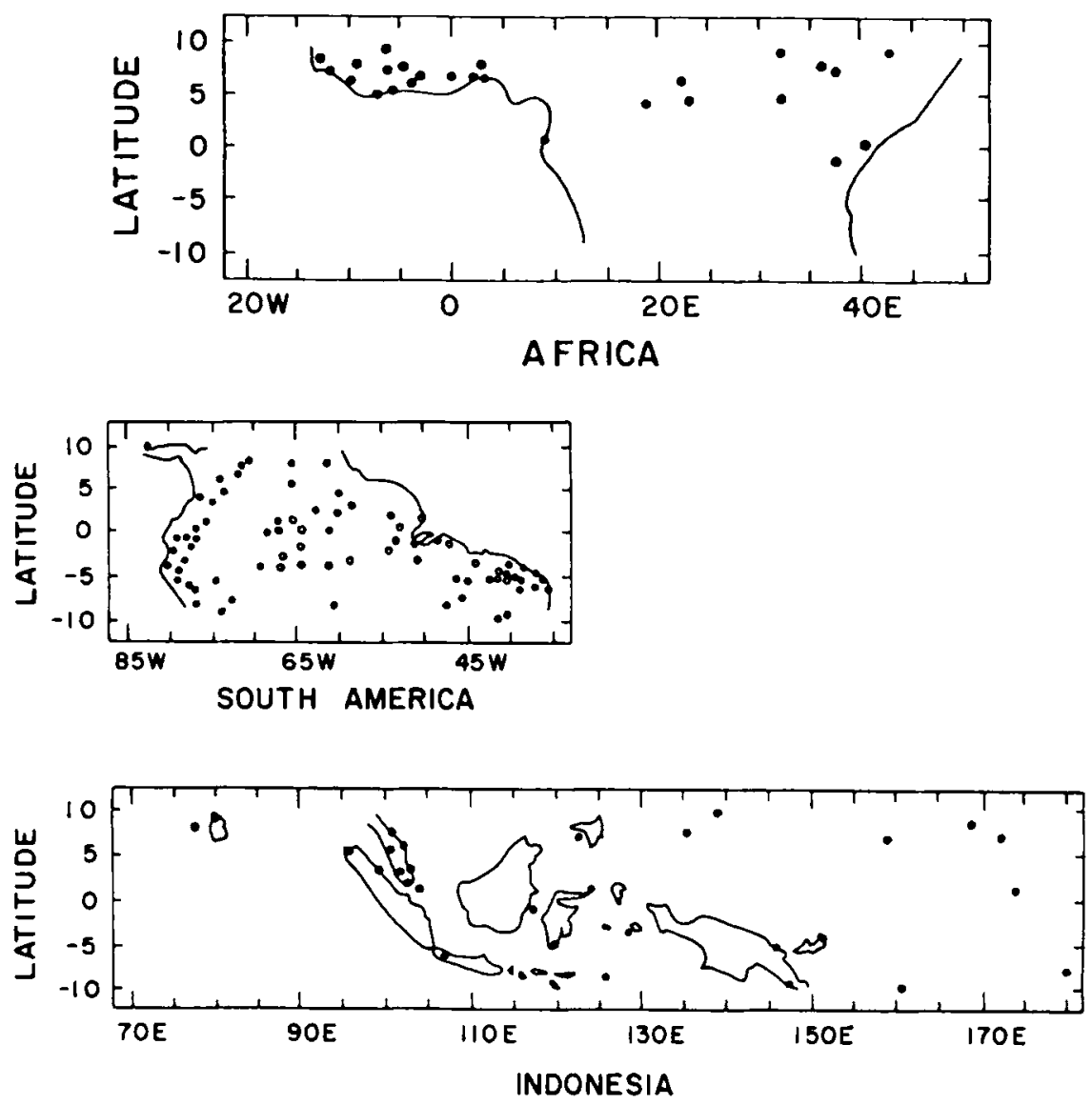

Figure 1. Location of the pluviometric stations represented by dots (long series data stations) and by circles (less than 10-year series data stations)

For the analyses of the equatorial circulations the mass adjusted kinematic vertical velocity in the pressure coordinate $(\omega)$ has been computed using the NMC wind data. The horizontal divergence field was smoothed using the formula

$$
\begin{aligned}
D_{\mathrm{s}}(i, j)= & \{4 D(i, j)+2[D(i, j-1)+D(i-1, j)+D(i, j+1)+D(i+1, j)]+D(i-1, j-1) \\
& +D(i+1, j-1)+D(i+1, j+1)+D(i-1, j+1)\} / 16
\end{aligned}
$$

where $D$ is the horizontal divergence, the indices $i$ and $j$ refer to latitude and longitude, respectively, and the subscript $\mathbf{s}$ refers to smoothed value. After application of this smoothing operator, $\omega$ was computed at each pressure level, through the use of the continuity equation and the assumption that $\omega=0$ at the $1000 \mathrm{mb}$ and $200 \mathrm{mb}$ levels.

The precipitation analyses are based on the 3-month period (December-February (DJF) 1982-1983 to September-November (SON) 1984) maps of precipitation deviation, normalized by the standard deviation, for the tropical areas of South America, Africa and the Indonesian region.

The equatorial circulation variations and the associated precipitation anomalies are examined in association with the SST, outgoing longwave radiation (OLR) and upper and lower level wind maps found in Arkin et al. (1983) and in the Climate Diagnostics Bulletin (1984a--d). 


\section{RESULTS AND DISCUSSION}

Vertical velocity variations during 1983 and 1984

Positive SST anomalies developed over the equatorial central Pacific around mid-1982 accompanied by anomalous low-level westerlies over the western Pacific. The low value of the SO (Rasmusson and Wallace, 1983) was due to the weakening of the south-east Pacific subtropical high and the low pressure system in the Indonesian region. These anomalous oceanic and atmospheric conditions were very intense at the beginning of 1983, when the SO index was as low as -3.0 times the standard deviation (see Climate Diagnostics Bulletin, 1984b).

Figures 2 and 3 show longitude vs altitude cross-sections of the vertical velocity and zonal wind (deviation from zonal mean) over the equator for DJF 1982-1983 and DJF 1983-1984. These equatorial circulations in the vertical zonal plane are related (not identical) to the Walker circulation (Troup, 1965) since only the divergent component of the zonal wind should be considered for the Walker circulation. In view of the crrors involved in computing the divergent component of the zonal wind we preferred the observed $u$ component to discuss the interannual variations. Further, it would be simpler to identify interannual variations in the directly measurable quantities. A reversal of the circulation over the equatorial Pacific and Indonesian region between these two periods can be noted. During DJF 1982-1983 rising motion prevailed over the central

DJF 1982-83

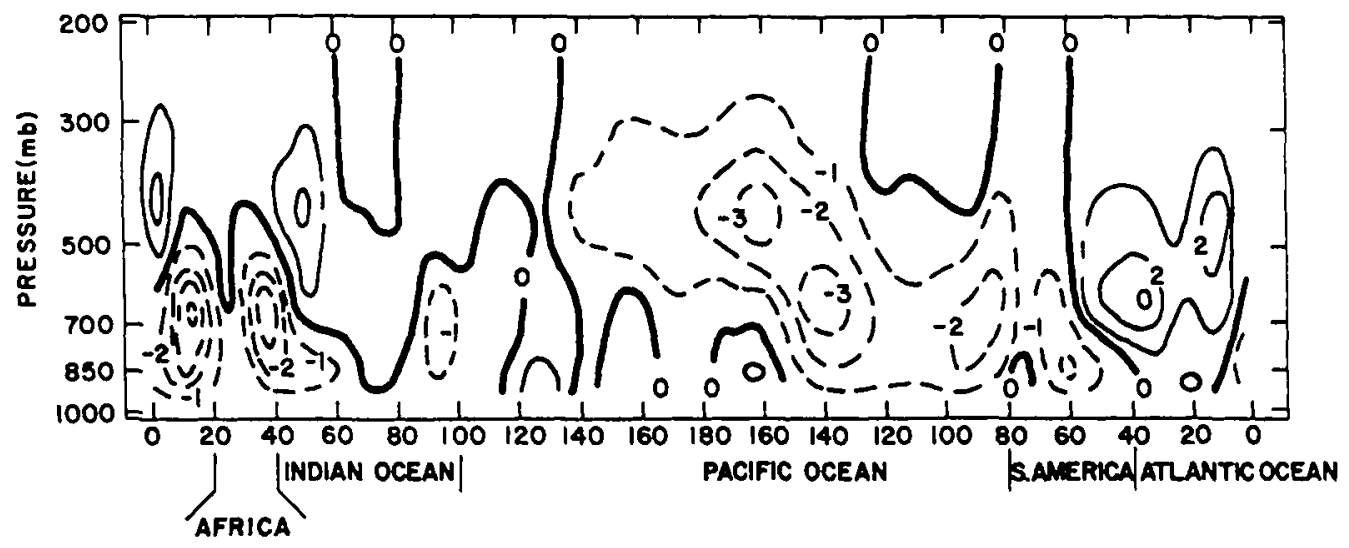

U' DJF $1982-83$

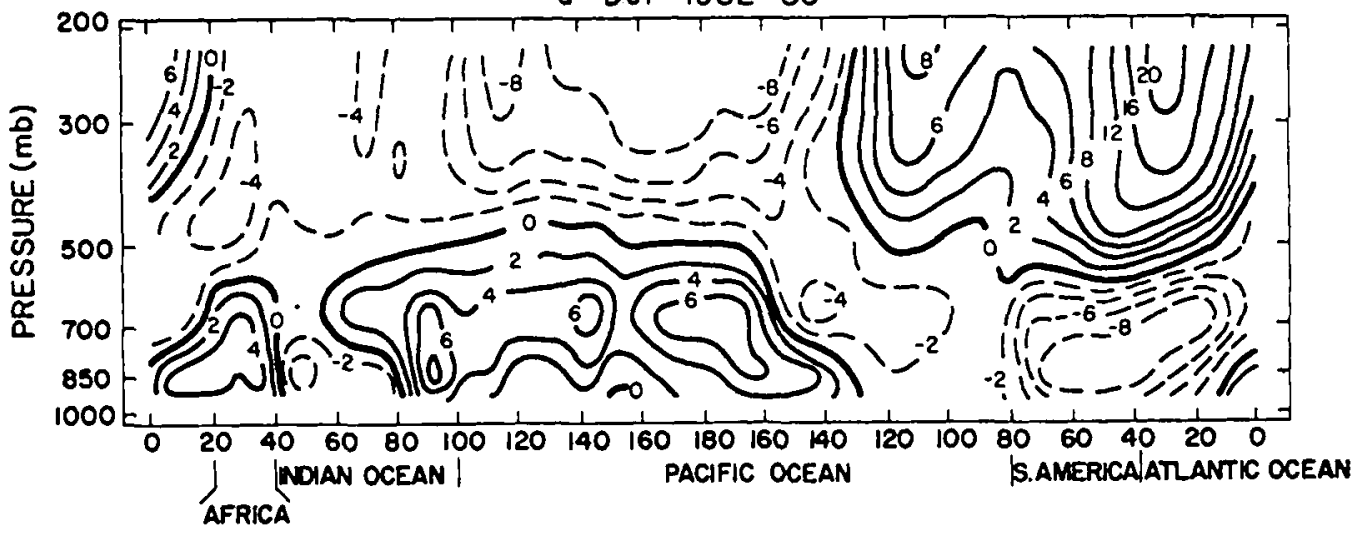

Figure 2. Vertical cross sections of the vertical velocity (top) and zonal wind deviation from the zonal average (bottom) at the equator for DJF 1982-1983. The broken lines are the negative isolines. For the vertical velocity the contour interval is $10^{-4} \mathrm{mb} \mathrm{s}^{-1}$. For the zonal wind the contours are $2 \mathrm{~m} \mathrm{~s}^{-1}$ for the isolines with absolute value lower than $8 \mathrm{~m} \mathrm{~s}^{-1}$, and $4 \mathrm{~m} \mathrm{~s}^{-1}$ for values greater than $8 \mathrm{~m} \mathrm{~s}-1$. 
DJF $1983-84$
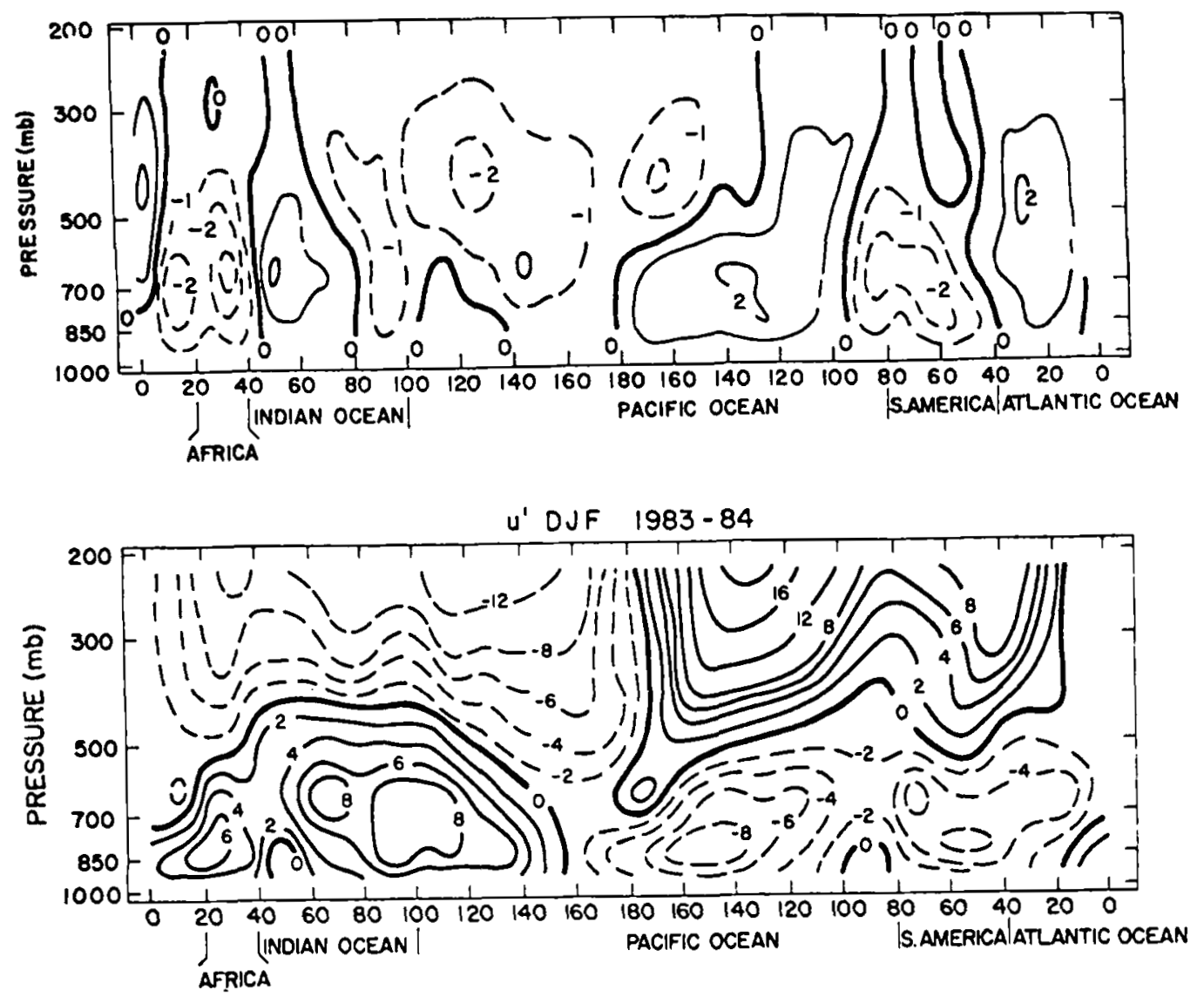

Figure 3. Same as Figure 2, except for DJF 1983-1984.

Pacific, with sinking to the east and to the west. In agreement with the vertical velocities, anomalous westerlies in the western Pacific and easterlies in the eastern Pacific were noted at lower levels. In the upper levels, casterlies in the western Pacific and westerlies in the eastern Pacific were noted. The observed vertical velocity and zonal wind patterns are consistent with contemporary theoretical notions (Matsuno, 1966; Gill 1980). Gill (1980) in an elegant analytical study on heat-induced equatorial circulations showed that rising motion occurs directly above the heat source with easterlies to the east of it and a smaller region of westerlies to the west. He interpreted this pattern in terms of equatorially trapped Kelvin and Rossby waves. When the heating is switched on at an initial time, Kelvin waves travel eastward creating easterlies to the east of the heating. Rossby waves that have a phase speed approximately one third of that of Kelvin wave speed travel westward. Because of the lower Rossby wave speed the region of westerlies to the west is more limited. Thus, easterlies to the east and westerlies to the west in the lower levels induce convergence and rising motion over the heat source. In the steady state the heating rate is balanced by the adiabatic cooling of the ascent.

Figure 4 shows a vertical time section of $\omega$ for the period December 1982 to December 1984 for two selected grid points. The grid point $\left(0^{\circ}, 105^{\circ} \mathrm{E}\right)$ chosen for the upper panel is very near Singapore while the bottom panel refers to a grid point $\left(10^{\circ} \mathrm{S}, 140^{\circ} \mathrm{W}\right)$ in the central Pacific near Atuona. (Hereafter we call these grid points Singapore and Atuona.) These two grid points were selected since the principal changes in the vertical motion occurred near these points, as mentioned earlier.

From the end of 1982 up to March 1983, there were positive SST anomalies in the central eastern Pacific (Arkin et al., 1983) establishing a diabatic (sensible) heat source. This heat source will create horizontal pressure gradients causing air to converge towards the heat source at low levels and rise. The water vapour in 

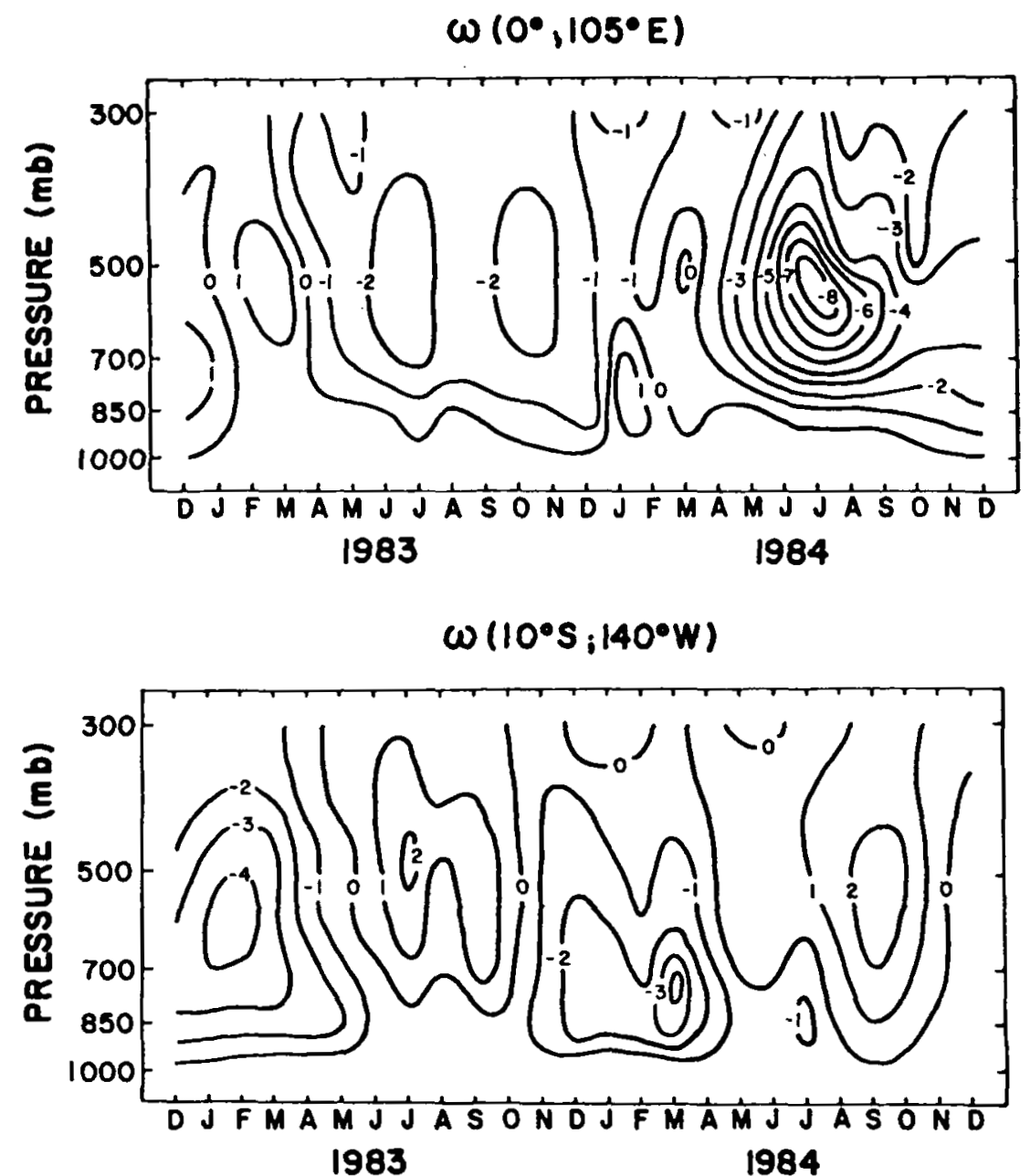

Figure 4. Vertical time section of $(1)$ at the Equator; $105^{\circ} \mathrm{E}$, the grid point nearest to Singapore (top) and at $10^{\circ} \mathrm{S} ; 140^{\circ} \mathrm{W}$ near Atuona (bottom). The contour interval is $10^{-4} \mathrm{mbs}^{-1}$.

the air will condense as it rises releasing latent heat. Thus, an atmospheric heat source is created over the SST anomaly. During December 1982 to March 1983, the heat-source inducing ascending motion over Atuona associated with low-level convergence and the high-level divergence and descending motion over Singapore determined the anomalous circulation. This situation prevailed during the mature phase of the 1982-1983 E1 Niño event. A detailed discussion of the subsequent change into a non-El-Niño situation, which started around April-May 1983, is given in Kayano (1986).

Here some interesting aspects of the tropical circulation that characterized the contrast between 1983 and 1984 are indicated. The rising motion observed over Atuona during the end of 1983 up to May 1984 was in a shallow layer and weaker than that noted during the period of 1982-1983. On the other hand, ascending motions were observed over Singapore during April-December of both years, a period which includes the summer monsoon season. The intensity of the rising motions was distinctly different in the monsoon seasons of 1983 and 1984 . The summer monsoon of 1983 was weak compared with that of 1984 , which was fully developed as evidenced by the strong upward motions.

The summer monsoon of 1983 over Indonesia established itself in an unusual tropical circulation so that its associated heat source and circulation (although weak) can be seen probably as a seasonal change that cooperated in the El Niño collapse, which started around April-May 1983. In contrast, the conditions of 1984 (non-ENSO) were close to normal, and the summer monsoon was well established. 


\section{DJF $1982-83$}
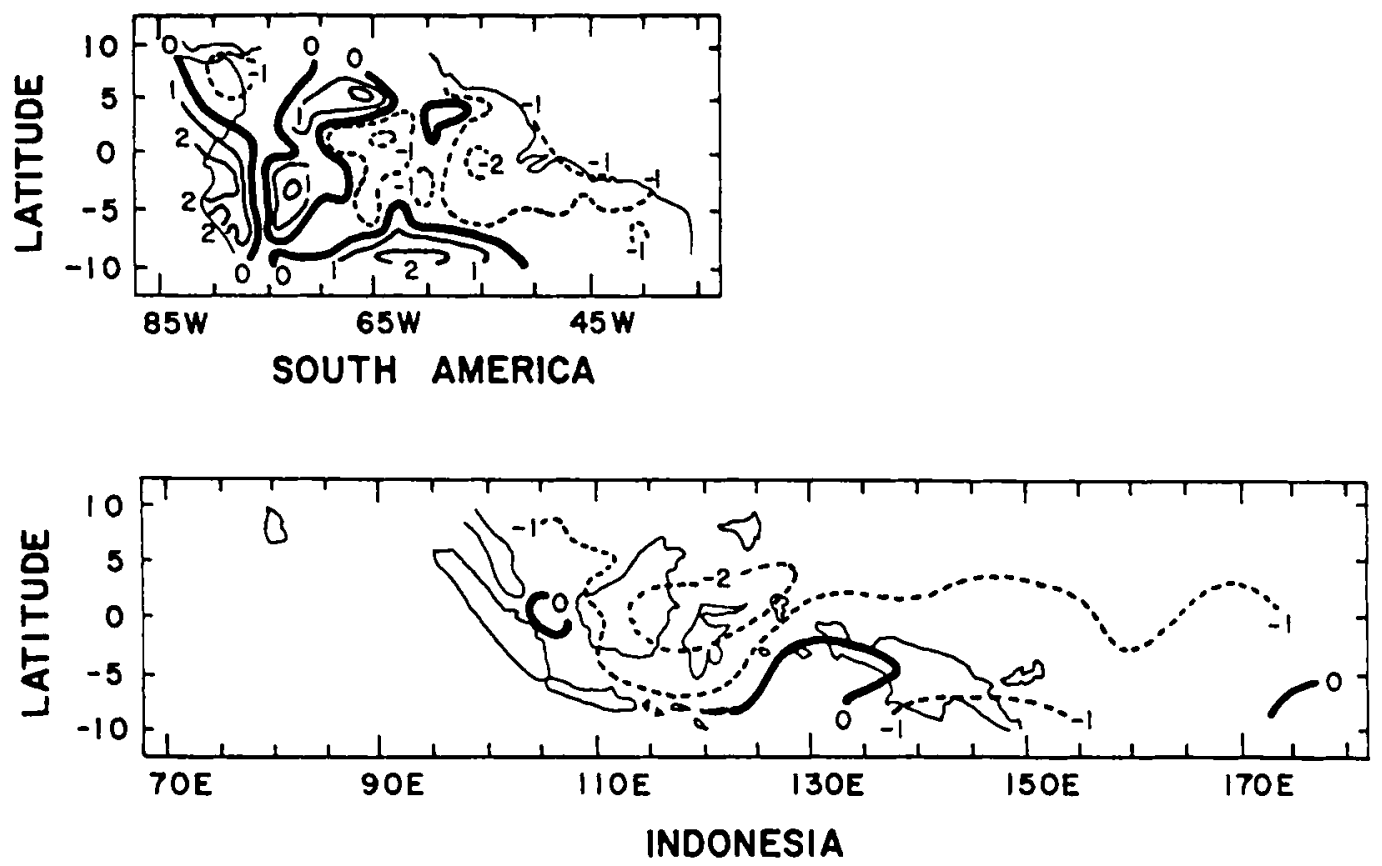

Figure 5. Seasonal rainfall departures normalized by the standard deviation for DJF 1982-1983 for the tropical zone (10 $\left.\mathrm{N} 10^{\prime \prime} \mathrm{S}\right)$ of South America and the Indonesian region. The broken lines are negative isolines. The contour interval is 1.

\section{Rainfall variations during 1983 and 1984}

The negative rainfall anomalies observed during DJF 1982-1983 over extensive tropical areas of South America (except over the coastal lands of Peru and Ecuador) and Indonesia (Figure 5) are consistent with the anomalous circulation associated with the heat source in the equatorial central Pacific, as discussed above. During DJF 1982-1983 the low-level convergence of moist air was associated with rising motion and enhanced the convective activity in the equatorial eastern Pacific, with heavy rainfall in this area and surroundings extending eastward as far as Ecuador and northwestern Peru (see OLR anomaly maps in Arkin et al., 1983). The rest of the tropical area of South America (the Amazon basin and north-east Brazil) and Indonesia, however, were under the influence of the descending motion of the anomalous equatorial circulation, so that convective activity was inhibited (Arkin et al., 1983) reducing the precipitation over these regions.

During DJF 1983-1984 these precipitation patterns almost reversed. Wet conditions were observed over the tropical lands of South America and Indonesia (Figure 6) and relatively dry conditions prevailed over the central Pacific region (Climate Diagnostic Bulletin, 1984b). Further, the heavy precipitation observed during DJF 1982-1983 and DJF 1983-1983 over Ecuador and north-western Peru was replaced by drier conditions during DJF 1983-1984. These climatic anomalies observed over the tropics during DJF 1982-1984 were related to the variations in the vertical motion. In both periods positive precipitation deviations were associated with the ascending motion while negative areas were observed in the region of descending motion.

As discussed above the change observed in the tropical circulation during May 1983 was also reflected in the precipitation anomalies of March-May (MAM) 1983 (not shown here). An increase of rainfall was verified in western Indonesia, which suggests the establishment of a secondary atmospheric heat source for the tropical circulation. Thus, gradually the atmospheric circulation pattern and the associated precipitation developed into a non-ENSO condition as shown in Figures 4 and 6.

The increase of rainfall in the Amazon and north-east Brazil during DJF 1983-1984 was related to rising 


\section{DJF $1983-84$}
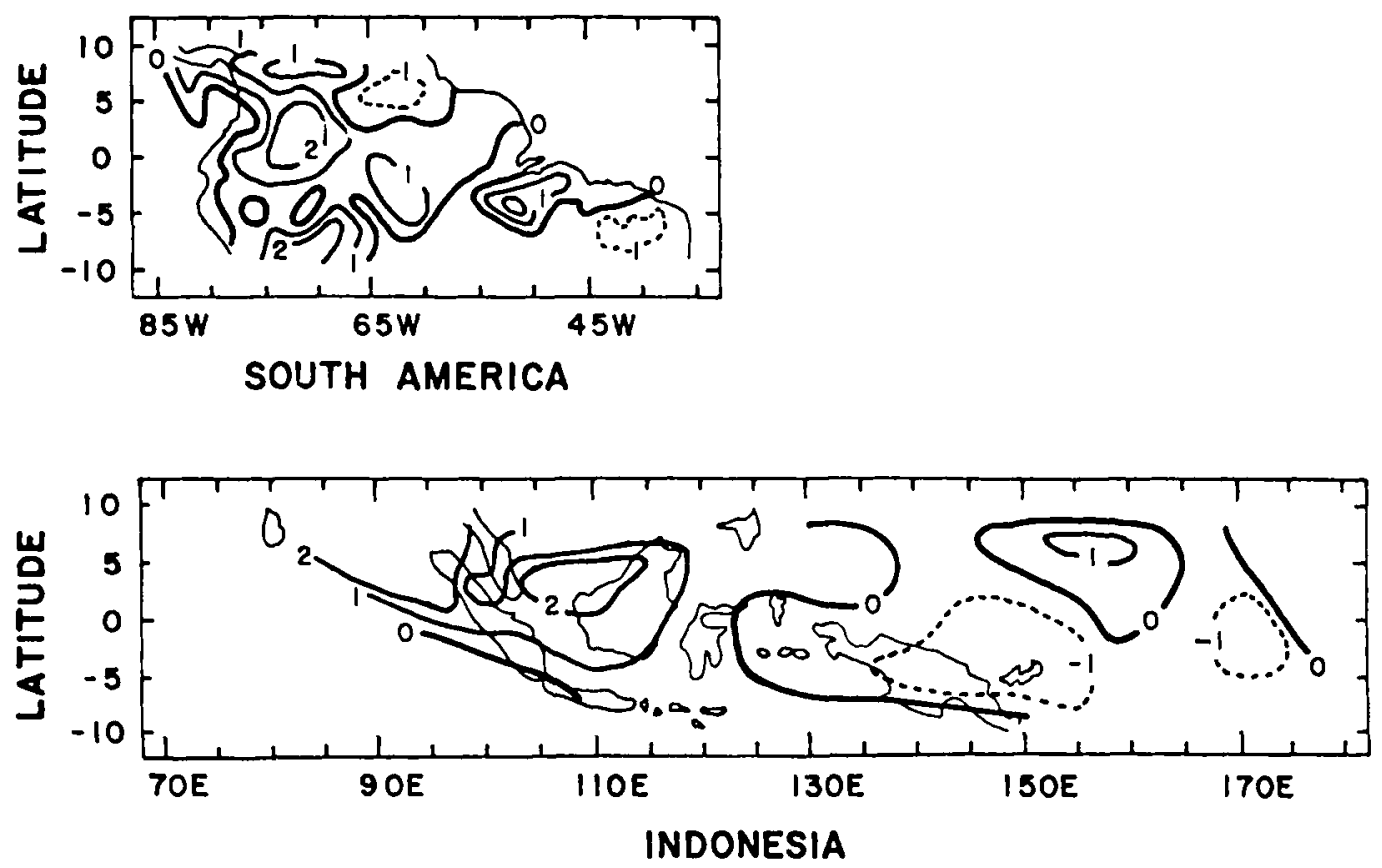

Figure 6. Same as Figure 4, except for DJF 19831984.

motions over these areas and seems also to be related to the variations in the tropical Atlantic SST. The slightly warmer than normal waters in the south Atlantic ocean (Climate Diagnostics Bulletin, 1984b) induced convergence at low levels, weakening the south Atlantic subtropical high. Under these conditions the intertropical convergence zone (ITCZ) moved to the south, increasing rainfall in the Amazon and north-east Brazil arcas.

On the other hand, the SST near Indonesia during DJF 1983-1984 was close to normal (Climate Diagnostics Bulletin, 1984b). However, excessive rainfall was observed over Indonesia, mainly in its western part, consistent with the rising motions verified in these regions.

Regarding the interannual variations of rainfall over Africa, Stockenius (1981) and WMO (1985) pointed out that the east-west circulation variations are important. Further, the Atlantic SSTs seem to play an important role in the tropical African precipitation, such that the SST pattern with positive anomalies over the north Atlantic and negative anomalies over the south Atlantic is related to extensive rainfall over the zone $10^{\circ} \mathrm{N} \cdots 10^{\circ} \mathrm{S}$ and lack of precipitation to the north (WMO, 1985). The north-south tropical trough migration also plays an important role in the tropical African precipitation (Riehl, 1979).

Throughout the analysed period (1982-1984) the region west of $20^{\circ} \mathrm{E}$ and between $10^{\circ} \mathrm{N}$ and $5^{\circ} \mathrm{N}$ experienced negative rainfall anomalies (Figure 7). This negative area was the southern extension of the extreme dry region of sub-Sahel (WMO, 1985). It is remarkable that the very dry areas are smaller in extension during DJF 1983 -1984 than during DJF 1982-1983.

\section{Rainfall characteristics over South America during January 1983 and January 1984}

Maps of monthly rainfall over South America normalized by the long-term mean for January 1983 and January 1984 are shown in the Figure $8 \mathrm{~b}$ and c, respectively. Figure 8 a gives the location of the pluviometric stations. 


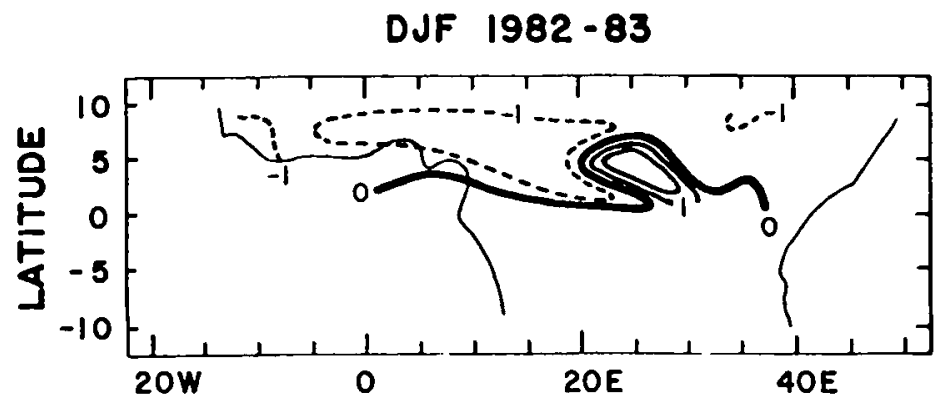

DJF $1983-84$

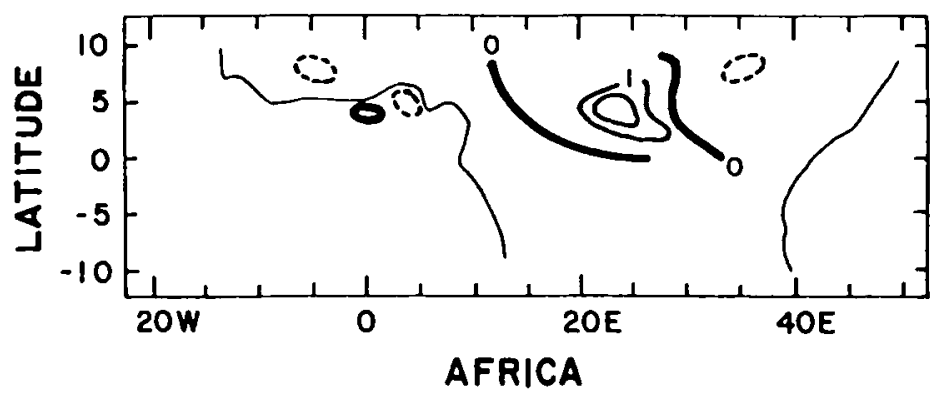

Figure 7. Seasonal rainfall departures normalized by the standard deviation for DJF 1982-1983 (top) and for DJF 1983-1984 (bottom) for the tropical zone of Africa. The broken lines are the negative isolines. The contour interval is 1 .

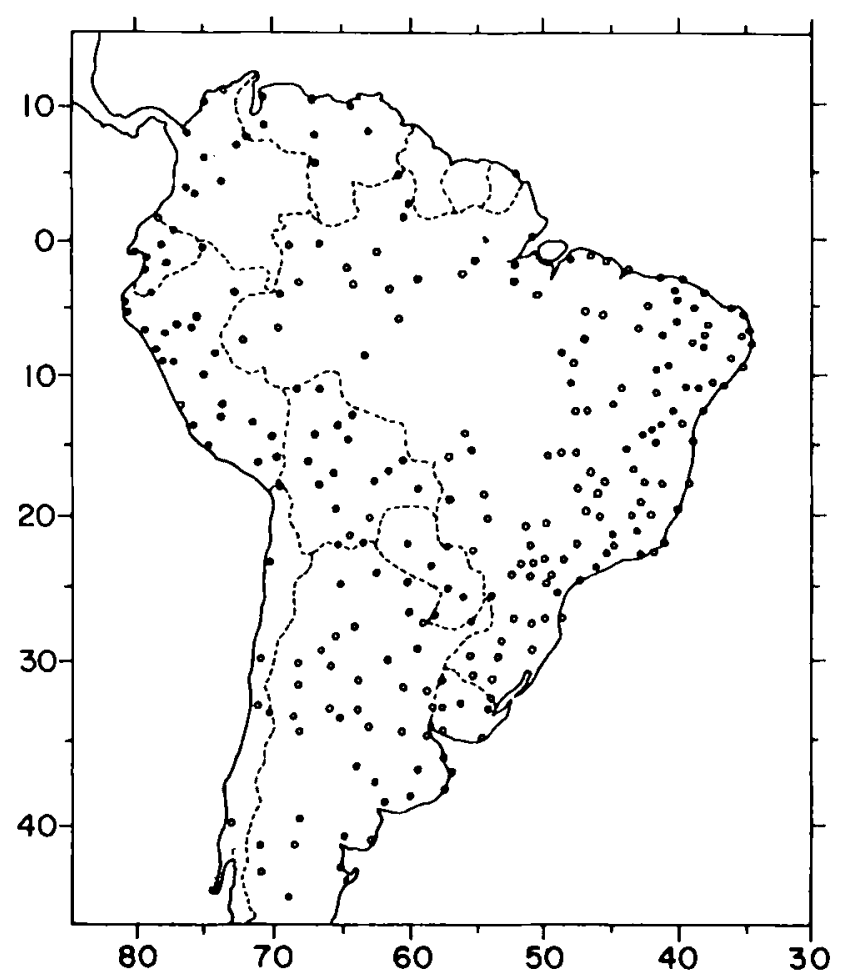

Figure 8. (a) Location of the pluviometric stations represented by dots (long series data stations) and by circles (auxiliary stations for which the precipitation deviations were used). (b) January 1983 monthly rainfall deviations normalized by the average. (c) January 1984 monthly rainfall deviations normalized by the average. 


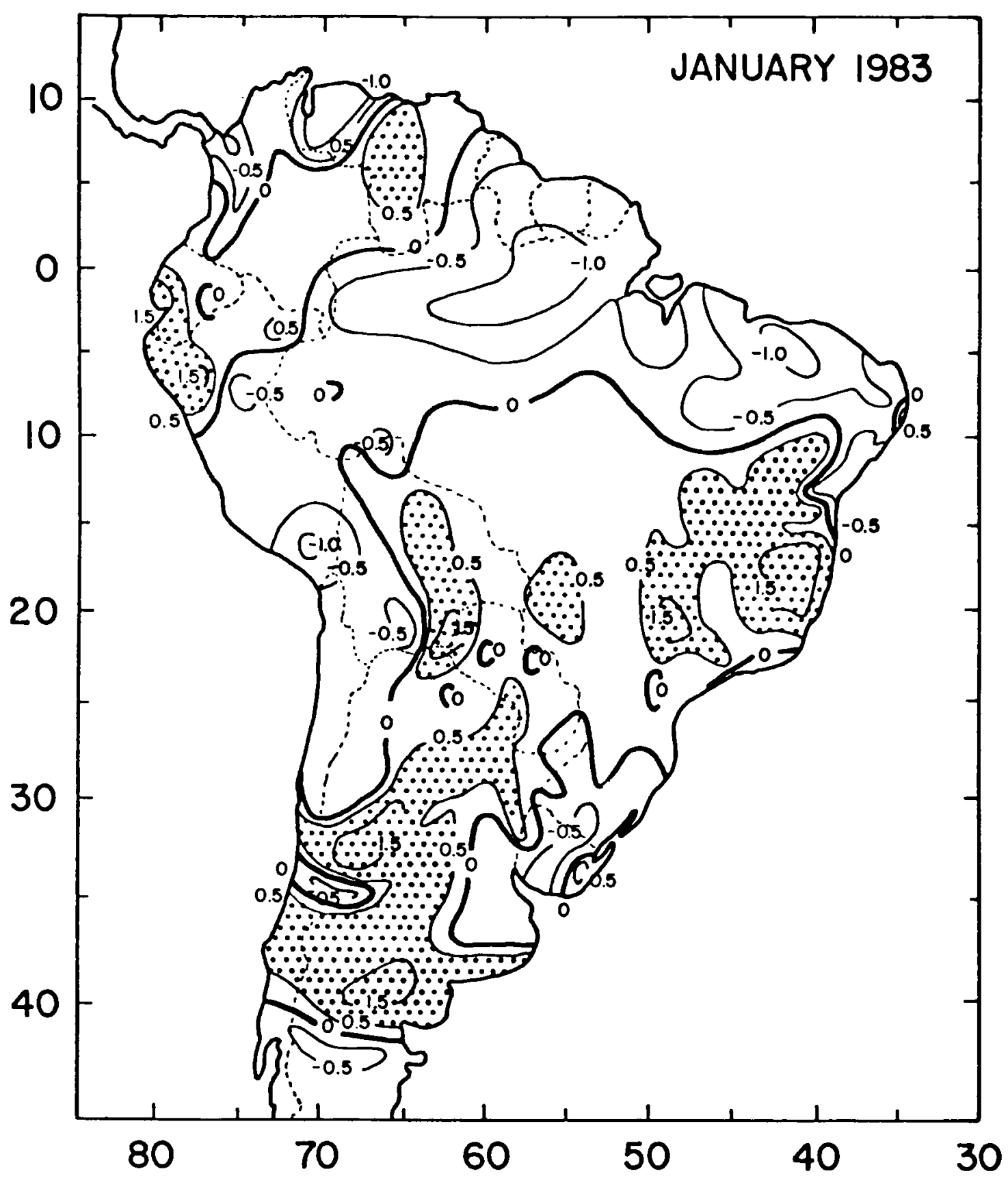

Figure 8 (b)

A careful comparison of the Figure $8 \mathrm{~b}$ and $\mathrm{c}$ shows the reversal of the precipitation deviation pattern between these two January months, over almost all of the South American region.

Heavy rainfall over Ecuador and north-western Peru during January 1983 associated with rising motion changed to drier conditions one year later. During January 1984, warm waters in the equatorial eastern Pacific observed at the beginning of 1983 were replaced by cooler waters (see Climate Diagnostics Bulletin, 1984a), so that the associated low-level convergence became weak and the descending motion took place in the equatorial eastern Pacific and surroundings, thus convection was inhibited over these regions. 


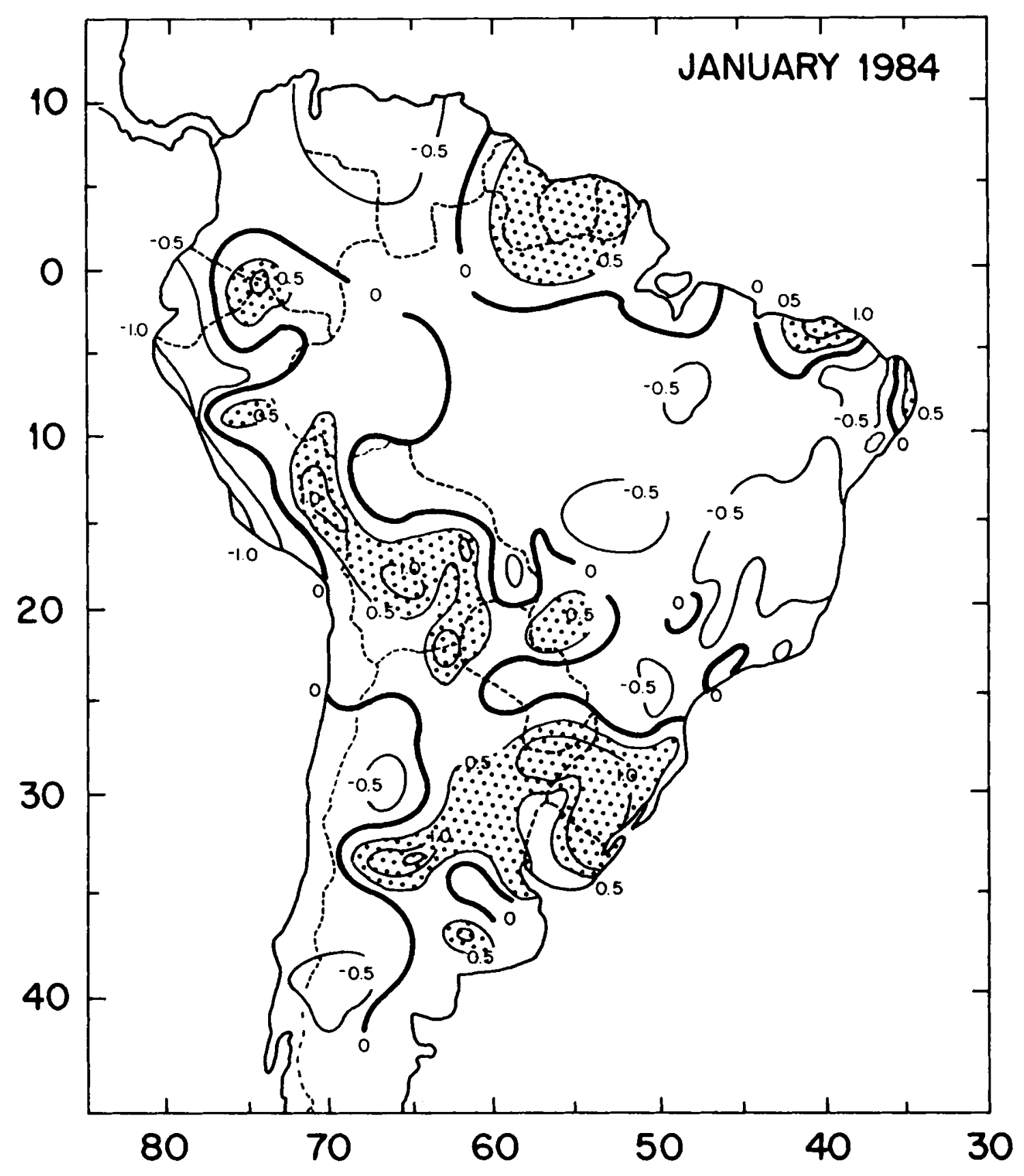

Figure 8 (c)

The precipitation over the western side of Amazonia increased during January 1984 compared to January 1983. It can be seen also that precipitation increased during January 1984 over the rest of the Amazon and over north-east Brazil, mainly over their northern portions. The rainfall distribution over these regions at the beginning of 1984 was probably due to the Atlantic SST changes. During January 1984 the south Atlantic SST anomalies presented positive values (see Climate Diagnostics Bulletin, 1984a). As mentioned in the last section this SST anomaly pattern favours the southward displacement of the ITCZ, which seems to increase 
precipitation over the Amazon and north-east Brazil. Therefore, there is evidence that as the effects of the ENSO event become weaker the tropical Atlantic SST variations play an important role in the precipitation of the northern portions of the Amazon and north-east Brazil.

Further, the central part of Brazil (approximately between $10^{\circ} \mathrm{S}$ and $22^{\circ} \mathrm{S}$ ), which experienced heavy precipitation during January 1983, was drier during January 1984. A reversal of patterns was also observed over southern Peru, western Bolivia, northern Chile and extreme north-western Argentina, with dry conditions during January 1983 and wetter conditions during January 1984.

The only region with the same pattern (positive precipitation deviation) during both January months extended over eastern Bolivia, Paraguay and the central part of Argentina. However, in almost all this area, the precipitation deviation values during January 1984 were smaller than during January 1983.

The above findings show that the mechanisms associated with the El Niño that caused dramatic climatic anomalies weakened and even reversed in some places with the collapse of the El Niño one year later.

\section{SUMMARY AND CONCLUSIONS}

The analyses of the large-scale tropical circulation variations during 1983 and 1984 revealed abnormal features associated with anomalous rainfall during these years. During 1983 dry conditions prevailed over extensive tropical lands (South America, Africa and Indonesia) and excessive rainfall occurred over the central Pacific. During 1984 these climate anomalies almost reversed, in agreement with the reversal of the tropical circulation characteristics. The analyses showed that the intensity and location of the ascending and descending motions of the equatorial circulations are consistent with OLR and precipitation anomalies. They also showed the importance of the north-south movement of the tropical trough in modulating tropical rainfall, mainly over the northern part of the Amazon and north-east Brazil.

Another aspect discussed refers to the tropical circulation changes from El Niño conditions to normal. Our analyses showed that the change started around May 1983 and this could be related to seasonal changes like the establishment of the summer monsoon in the Indian ocean and western Indonesia, with the development of a secondary heat source there, as evidenced by the increase of rainfall over western Indonesia during MAM 1983. Our results suggest that seasonal changes were involved in the 1982-1983 El Niño collapse.

\section{ACKNOWLEDGEMENTS}

This paper is taken from the doctoral thesis of the first author. Thanks are due to Dr. Prakki Satyamurti for going through the manuscript.

\section{REFERENCES}

Arkin, P. A., Kopman, J. D. and Reynolds, R. W. 1983. '1982-1983 El Niño/Southern Oscillation Event Quick Look Atlas', NOAA, Climate Analysis Center, Washington, DC.

Chen, W. Y. 1983. 'The climate of spring 1983-a season with persistent global anomalies associated with El Niño', Mon. Wea. Ret., 111, 2371-2384.

Climate Diagnostics Bulletin, 1984a. 'Global analyses and indices', National Meteorological Center, Washington, DC, 84/2.

Climate Diagnostics Bulletin. 1984b, 'Global analyses and indices', National Meteorological center, Washington, DC, 84/3.

Climate Diagnostics Bulletin. 1984c, 'Global Analyses and Indices', National Meteorological center, Washington, DC, 84/6.

Climate Diagnostics Bulletin. 1984d, 'Global analyses and indices', National Meteorological Center, Washington, DC, 84/9.

Gill, A. E. 1980. 'Some simple solutions for heat-induced tropical circulation', Q. J. R. Meteorol. Soc., 106, 447 462.

Horel, J. D., Kousky, V. E. and Kagano, M. T. 1986. 'Atmospheric conditions in the Atlantic sector during 1983 and 1984', Nature, 322, 248-251.

Kayano, M. T. 1986. 'Variaçōes das circulações tropicais e as anomalias de precipitação associadas em dois anos de contraste', Ph. D. thesis, Instituto de Pesquisas Espaciais, Sào José dos Campos, SP, Brasil.

Kousky, V. E., Kagano, M. T. and Cavalcanti, I. F. A. 1984. 'A review of Southern Oscillation: oceanic-atmospheric circulation changes and related rainfall anomalies', Tellus, 36A, 490-504.

Krueger, A. F. 1983. 'The climate of autumn 1982--with a discussion of the major tropical Pacific anomaly', Mon. Wea. Ret., 111, 1103-118.

Matsuno, T. 1966. 'Quasi-geostrophic motions in the equatorial area', J. Meteorol. Soc. Japan, 44, $25-42$. 
Quiroz, R. S. 1983. 'The climate of the El Niño winter of 1982-83 a season of extraordinary climatic anomalies', Mon. Wea. Ret., 111, $1685-1706$.

Rasmusson. F. M. and Wallace, J. M. 1983. 'Meteorological aspects of the El Niño/Southern Oscillation', Science, 222, $1195-1202$.

Riehl, H. 1979. Climate and Weather in the Tropics, 2nd edn, Academic Press, London, 611 pp.

Stockenius, T. 1981. 'Interannual variations of tropical precipitation patterns', Mon. Wea. Rel., 109, 1233-1247.

Troup, A. J. 'The Southern Oscillation', Q. J. R. Meteorol. Soc., 91, 490-506.

WMO.(World Metcorological Organization) 1985. 'The Glohal climate System: a Critical Review of the climate System during 1982-1984, edited by WMO, Geneva, Switzerland, 52 pp. 